\title{
Finite Element Analysis of Stress in Anterior Prosthetic Rehabilitation with Zirconia Implants with and without Cantilever
}

\author{
Karina Tiemi Sanomya Tsumanuma ${ }^{1}$ Ricardo Armini Caldas ${ }^{2} \quad$ Isaias Donizeti Silva ${ }^{3}$ \\ Milton Edson Miranda ${ }^{1}$ William Cunha Brandt ${ }^{3}$ Rafael Pino Vitti ${ }^{4}$
}

1School of Dentistry, São Leopoldo Mandic, Campinas, São Paulo,

Address for correspondence Rafael Pino Vitti, DDS, MSc, PhD, Brazil

${ }^{2}$ School of Dentistry, Federal University of Santa Catarina, Florianópolis, Santa Catarina, Brazil

${ }^{3}$ School of Dentistry, Santo Amaro University, São Paulo, Brazil

${ }^{4}$ School of Dentistry, Herminio Ometto University Center, Araras,

São Paulo, Brazil

Eur J Dent 2021;15:669-674. \author{
Herminio Ometto University Center, Avenue Dr. Maximiliano Baruto, \\ 500, Araras, São Paulo 13607-339, Brazil \\ (e-mail: rafapvitti@gmail.com).
}

\begin{abstract}
Keywords

- zirconia implants

- cantilever

- finite element analysis

- rehabilitation

Objectives The aim of this study was to evaluate using finite element analysis (FEA), the stress distribution in prostheses (lithium disilicate crowns) on monotype zirconia implants with and without cantilever in the anterior region of the maxilla.

Materials and Methods From a virtual reconstruction of bone model of the toothed maxilla from a computed tomography, three models (groups) were created: $\mathrm{Zr}$ (1121)-implants placed in the area of 11 and 21 with cantilever; $\operatorname{Zr}(12-22)$-implants placed in the area of 12 and 22 without cantilever; and $\mathrm{Zr}$ (11-22)-implants intercalated placed in the area of 11 and 22 . In all models, monotype zirconia implant $(4.1 \times 12.0 \mathrm{~mm})$ was used in single-body configuration. Lithium disilicate crowns were designed on the implants and pontics for all groups. A 150-N load was applied to the prostheses. The materials used were considered isotropic, homogeneous, and linearly elastic. FEA was performed to evaluate the maximum (tensile) and minimum (compressive) principal stresses in the implant, crowns, and bone tissue. Data were analyzed qualitatively and quantitatively.

Results For all groups, the highest maximum principal stress occurred in the palatal cervical area of the implant, with the high values for the $\mathrm{Zr}$ (12-22) group and the low values for the $\mathrm{Zr}(11-21)$ group. The maximum principal stress was concentrated in the cervical palatal area of the crown, with the $\mathrm{Zr}(11-21)$ group presented the highest values and the $\mathrm{Zr}(12-22)$ group showed the lowest values. In the bone tissue all the groups presented similar values of maximum and minimal principal stress, with the palatal (maximum principal) and vestibular (minimum principal) close to the cervical of the implants the area with the highest concentration of stresses.

Conclusions The position of monotype zirconia implant did not interfere in the bone tissue stress, and the implants placed in the 11-21 present lower stress in implants and higher in the crown. The cantilever does not increase the stress in the implants, crown, and bone tissue.
\end{abstract}

published online August 12, 2021
DOI https://doi.org/ $10.1055 / \mathrm{s}-0041-1727544$ ISSN 1305-7456
(C) 2021. European Journal of Dentistry.

This is an open access article published by Thieme under the terms of the Creative Commons Attribution-NonDerivative-NonCommercial-License, permitting copying and reproduction so long as the original work is given appropriate credit. Contents may not be used for commercial purposes, or adapted, remixed, transformed or built upon. (https://creativecommons.org/licenses/by-nc-nd/4.0/).

Thieme Medical and Scientific Publishers Pvt. Ltd. A-12, 2nd Floor, Sector 2, Noida-201301 UP, India 


\section{Introduction}

The choice of the material used in implants, its positioning and installation, are determining factors in the rehabilitation of the anterior maxillary region. ${ }^{1,2}$ Ceramic materials such as yttrium-stabilized zirconia are an aesthetic alternative to the titanium implant ${ }^{2-4}$ especially in patients with thin peri-implant gingival tissue, ${ }^{4}$ gingival smile, or high aesthetic line, and in cases of bone resorption followed by gingival retraction and exposure of part of the implant. ${ }^{3}$ Besides, when there is a crack propagation, the yttrium-stabilized zirconia presents a volumetric expansion, which submits the crack under compressive tension and against its progression. ${ }^{4}$

The presence of anatomical structures, such as nasal fossa and bone deficiencies associated with a low density of the cancellous bone, promotes a restriction in the number, position, length, and width of the implants in the anterior region of the maxilla., ${ }^{5,6}$ Thus, the cantilever prosthesis is a viable option due to the possibility of preserving the bone crest necessary for the maintenance of the interdental papilla. ${ }^{1}$ Moreover, the cantilever prostheses should be used in clinical situations where patients do not have severe occlusal forces, such as in cases of parafunctional habits and places with adequate bone density, especially in previous rehabilitation. ${ }^{1,7,8}$ The use of cantilevered prostheses is a good alternative in places with bone defects, avoiding the need for surgery to place a bone graft prior to dental implantation. In addition, these prostheses are effective when the patient has anatomical limitations, such as extension of the maxillary sinus in previous maxillary rehabilitation. ${ }^{1}$

Another treatment option in the case of anterior edentulous areas is the placement of two implants in the region of the lateral incisors, ${ }^{9,10}$ as this allows the dental technician to manufacture central bridges with the necessary aesthetic and functional dimensions, in addition to favoring aesthetics and manipulation of soft tissue. ${ }^{1,10}$ Scientific studies that address this theme show divergent results in several factors, which hinders the comparison between studies. ${ }^{1,9,10}$

Currently, the advances in image processing and analysis techniques through software have been changing the reality in Dentistry. Digitization is widely used in studies as well as dental clinic in several areas, such as in radiology, orthodontics, implantology, and prosthodontics. Finite element analysis (FEA) is used in Dentistry to study how an implant and prosthodontics structures will respond to complex stress loading

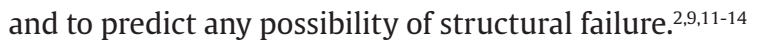

Thus, the aim of the present study was to verify the stress distribution in the implant, crown, and bone tissue in zirconia implants (single-body configuration) placed in different positions in the anterior region of the maxilla (12-22) in rehabilitation with and without a cantilever. The tested hypothesis is that implants placed on central incisors (11-21; with cantilever) would have lower mechanical performance compared with the other groups.

\section{Materials and Methods}

The bone model was acquired from images obtained from the toothed maxilla using computed tomography (i-CT Cone
Beam 3D Dental Imaging System, Imaging Sciences International; Hatfield, Pennsylvania, United States). This model consisted of a real geometric representation of the upper maxillary arch (18.0 mm height $\times 19.0 \mathrm{~mm}$ mesiodistal width $\times 15.0 \mathrm{~mm}$ buccolingual depth) with type three bone (thin layer of cortical bone-1.0 mm-around a cancellous bone) concerning its density. The purpose of tomography was to provide a bone-based model for the positioning of implants and subsequent manufacture of prostheses for simulation.

Three models were made in finite elements using a software (SolidWorks; SolidWorks Corporation, Concord, Massachusetts, United States). For all groups, a monotype zirconia implant (single-body zirconia configuration; $4.1 \times$ $12.0 \mathrm{~mm}$ implant) with prosthetic lithium disilicate crowns ( $0.5 \mathrm{~mm}$ thickness) was simulated using images obtained by computed microtomography. The drawings were standardized and three-dimensional computational models were generated, following the standards of conventional fixed partial and cantilever prostheses (-Fig. 1). The models were divided according to the placement of the implants in three groups:

$\operatorname{Zr}(11-21)$ : implants in regions 11 and 21 with cantilever.

$\mathrm{Zr}$ (12-22): implants in regions 12 and 22 without cantilever.

$\operatorname{Zr}(11-22)$ : intercalated implants in regions 11 and 22.
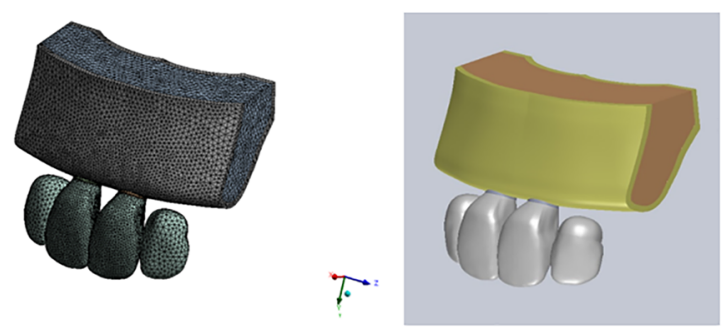

A
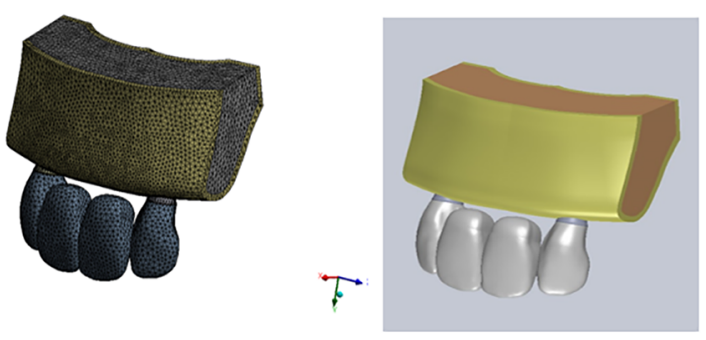

B
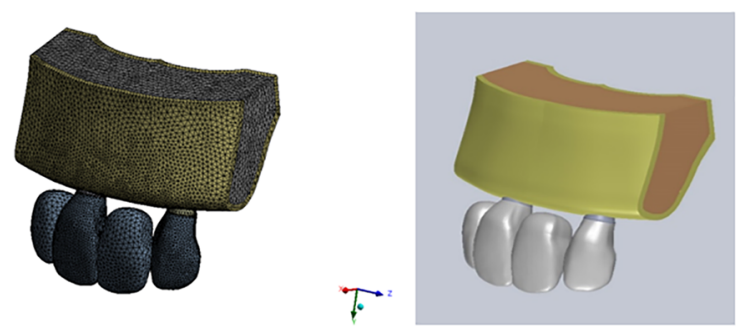

C

Fig. 1 Drawings (mesh and geometric) of the groups tested (A) $\mathrm{Zr}$ (11-21), (B) $\operatorname{Zr}(12-22)$, and (C) $\operatorname{Zr}(11-22)$. 
Table 1 Physical properties of the materials used

\begin{tabular}{|l|l|l|}
\hline Material & $\begin{array}{l}\text { Modulus of } \\
\text { elasticity (GPa) }\end{array}$ & Poisson's ratio \\
\hline Cortical bone & $13.7^{29}$ & $0.30^{29}$ \\
\hline Cancellous bone & $1.37^{29}$ & $0.30^{29}$ \\
\hline Zirconia & $200^{29}$ & $0.31^{29}$ \\
\hline Lithium disilicate & $68^{30}$ & $0.24^{30}$ \\
\hline
\end{tabular}

Source: Adapted from Çaglar et al $2011^{29}$ and Ereifej et al $2011^{30}$.

The implants were positioned parallel to their long axis on the bone base from tomography, and the implant platform was positioned at the height of the bone crest with standardization of the bone ridge. All implants were considered totally osseointegrated. The materials were considered isotropic, homogeneous, and linearly elastic. The values of the Young's modulus and the Poisson's ratio are described in - Table $\mathbf{1}$.

Then, the models were imported into the ANSYS Workbench 14.0 software (Swanson Analysis Systems Inc.; Houston, Pennsylvania, United States) for FEA. For all groups, an oblique load of $150 \mathrm{~N}$ at 45 degrees was applied to 11 and 21 axes, at the palatal portion of the prosthetic crowns. The oblique load results in harmful tensile/compression stresses and $150 \mathrm{~N}$ is the mean load applied on anterior teeth as well as used in several studies. ${ }^{2,10,15}$ The results were evaluated qualitatively and quantitatively by maximum principal $\mathrm{N}$ stress (tensile) and minimum principal stress (compressive) in the implant, crown, and bone tissue.

\section{Results}

In all considered positions, the cervical palatal region of the implant was where the highest concentrations of the maximum principal stress occurred, with the worst result for the $\mathrm{Zr}$ (12-22) group where the highest values of the maximum principal stress occurred (2.05 $\mathrm{MPa})$. The best result was found in the $\mathrm{Zr}$ (11-21) group where the lowest values of the maximum principal stress (1.53 MPa) occurred (-Fig. 2).

Concerning bone tissue, the maximum principal stress was greater in the palatal region near the cervical of the implants. Small differences can be observed regarding the distribution of these stresses among the groups evaluated. In addition, the different groups tested showed similar maximum values for the intensity of the maximum principal stress (approximately 8.0 MPa) (-Fig. 3).

In - Fig. 4, it was observed qualitatively and quantitatively that the minimum principal stress in bone tissue was concentrated in the vestibular region of bone tissue close to the implants. Equally to the maximum principal stress, a great similarity can be observed in the intensity (approximately 9.0 MPa) and the form of distribution of the minimum principal stress.

Regarding the ceramic crown, the maximum principal stress was concentrated in the cervical palatal region of the crown. The $\mathrm{Zr}$ (11-21) group presented the highest values of the maximum principal stress (8.05 MPa). The $\mathrm{Zr}$ (12-22) group showed the lowest values of the maximum principal

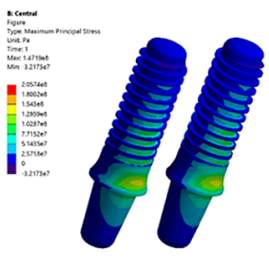

A

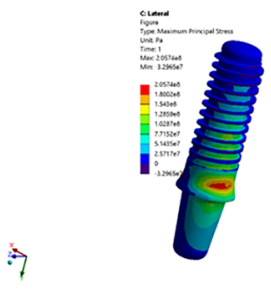

B

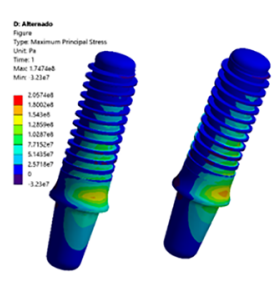

$\rightarrow$

$\mathrm{C}$

Fig. 2 Vestibular view of the implants showing the distribution of the maximum principal stress on the implants in the groups (A) $\operatorname{Zr}(11-21),(B) \operatorname{Zr}(12-22)$, and (C) $\operatorname{Zr}(11-22)$.
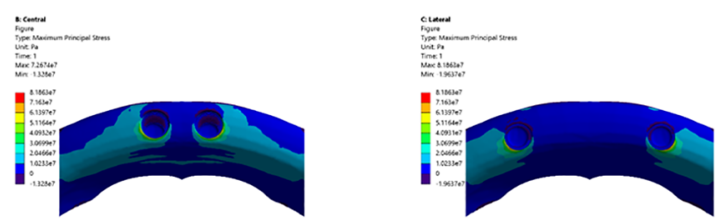

$\dot{L}$

A

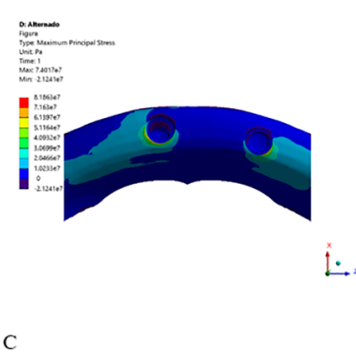

Fig. 3 Distribution of the maximum principal stress on bone tissue in the groups (A) Zr (11-21), (B) Zr (12-22), and (C) Zr (11-22).

stress (5.47 MPa). The $\mathrm{Zr}(11-22)$ group, on the other hand, showed intermediate maximum stress values between the two groups, but presented similar stress in the two elements, there was a higher concentration of stress in element 21 compared with element 22 ( - Fig. 5).

- Table 2 shows the maximum principal stress and minimum principal stress in implant, bone tissue, and crown for all groups tested.

\section{Discussion}

The hypothesis tested was rejected since the implants in the region of the central incisors (11-21) had a lower concentration of stress, and the stress transmitted to bone tissue was equivalent between the three groups tested. 

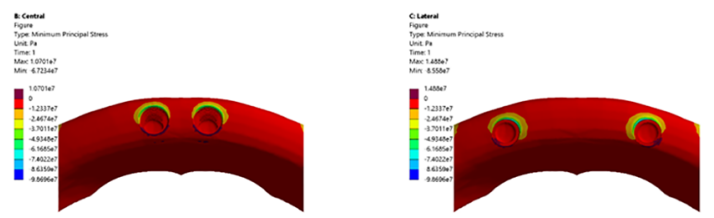

$\dot{L}$

A

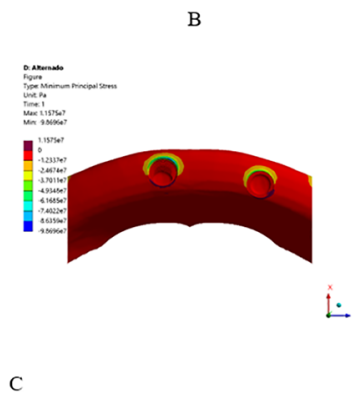

Fig. 4 Distribution of minimum principal stress on bone tissue in groups (A) Zr (11-21), (B) Zr (12-22), and (C) Zr (11-22).

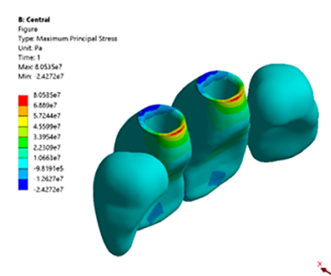

7

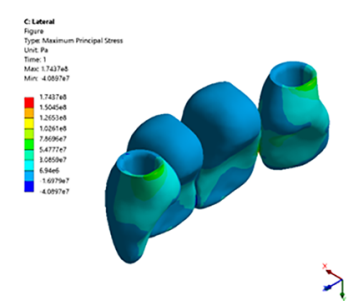

B

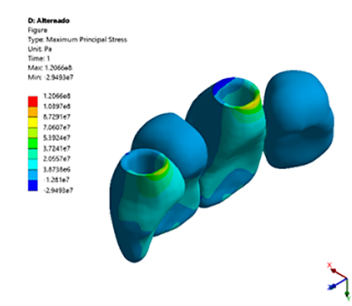

C

Fig. 5 Distribution of maximum principal stress on the crown in the groups (A) Zr (11-21), (B) Zr (12-22), and (C) Zr (11-22).

The lower concentration of stress in the implant and crown in $\mathrm{Zr}(11-21)$ group can be explained by the presence of the cantilever. The positioning of the implant adjacent to the cantilever does not promote problems in the prosthesis or bone resorption as long as the position and extension of even one dental element from the implant to the cantilever is respected, ${ }^{15}$ as in the current study. On other hand, a study ${ }^{7}$ showed that these variables (position and extension of the cantilever), since the greater extension and distance of the implants increase the prosthesis lever arm, consequently increases the accumulated stress in the prosthetic components. Thus, the presence of the cantilever does not increase the stress that is transferred to the implants, crown, and bone tissue.
Table 2 Maximum principal stress and minimum principal stress (MPa) in implant, bone tissue, and crown for all groups tested

\begin{tabular}{|l|l|l|l|}
\hline & & $\begin{array}{l}\text { Maximum } \\
\text { principal } \\
\text { stress }\end{array}$ & $\begin{array}{l}\text { Minimum } \\
\text { principal } \\
\text { stress }\end{array}$ \\
\hline \multirow{3}{*}{$\operatorname{Zr}(11-21)$} & Implant & 1.53 & - \\
\cline { 2 - 4 } & Crown & 8.05 & - \\
\cline { 2 - 4 } & Bone tissue & 6.13 & 7.40 \\
\hline \multirow{2}{*}{$\operatorname{rr}(12-22)$} & Implant & 2.05 & - \\
\cline { 2 - 4 } & Crown & 5.47 & - \\
\cline { 2 - 4 } & Bone tissue & 8.18 & 9.86 \\
\hline $\operatorname{Zr}(11-22)$ & Implant & 1.80 & - \\
\cline { 2 - 4 } & Crown & 7.06 & - \\
\cline { 2 - 4 } & Bone tissue & 7.16 & 9.86 \\
\hline
\end{tabular}

In the implants, the stress concentration was located in the cervical palatal region of the implants. This is due to the macrogeometry of the monotype zirconia implant, which provides a more uniform stress distribution in its body and more concentrated in the region of the implant neck and the alveolar region of the bone tissue., 2,16,17

Regarding the load distribution in bone tissue, this study showed that the stress distribution was equivalent in the three groups studied, with the tensile stress being concentrated in the palatal region where the bone is in contact with the neck (first threads) of the implant and compressive stress concentrated in the vestibular region of the bone tissue close to the implants. The positioning of the implants $1 \mathrm{~mm}$ below the bone cortex, as in the current study, provides better dissipation of masticatory loads in bone tissue. ${ }^{18-21}$ Thus, the position of the implants within the bone tissue influences the stress distribution in the bone more than the presence of the cantilever or the positioning of the implants in the different anterior regions evaluated (11-21, 12-22, and 11-22). The stress distribution in bone tissue is influenced, in addition to the macrogeometry of the monotype zirconia implant, by the type of bone tissue and the direction of the applied load. 2,10,22 In low-density bone tissue, stress is distributed over a larger area around the apex, while in high-density bone, stress is more concentrated in the cervical region. ${ }^{2,6,19}$ In the direction of the applied load, the oblique inclination of the load directs the stresses to the areas where there was compression, influencing the biomechanical performance of implant-supported rehabilitation. ${ }^{22,23}$

All groups showed adequate levels of bioperformance (ratio $<1$ ), with stress values below the critical limit that the cortical bone can receive without suffering damage, such as plastic deformations (beginning of the bone resorption process) or fracture. ${ }^{2,24}$

The results are also linked to the type of load applied in the study. Thus, differences found between the results of current study and the literature can also be explained by the intensity and inclination of the load, since different loads form different lever arms in monotype zirconia implants, 
increasing the stresses in the regions of rotational fulcrum and bone crest..$^{5,20,25-28}$ Furthermore, the results of this study (monotype zirconia implant) showed lower stress values

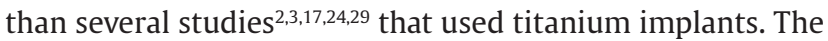
highest Young's Modulus for zirconia (200 GPa; - Table 1) in relation to the titanium ( $115 \mathrm{GPa})^{29}$ could explain this difference. A high Young's Modulus (elasticity) causes low stress in crown, implant, and bone as well as less bone resorption in the peri-implant region against occlusal load. ${ }^{29}$

There is still controversy regarding the planning and location of implants in cases of anterior maxillary rehabilitation. Despite the values considered in this study to be adequate, it is important to consider the limitations inherent in any academic study. In the current study, we did not consider different occlusal patterns, parafunctional habits, greater extension of the prosthetic space, in addition to the quality of bone tissue and the prolonged use of the prosthesis, which could maximize transferred stress and generate system overload, affecting the prognosis of the rehabilitating treatment. ${ }^{6,8,10,15,16,30}$ Thus, future research on this topic is needed to assess the longevity of anterior maxillary rehabilitation with monotype zirconia implants with and without cantilever.

\section{Conclusion}

According to the results obtained, it is concluded that (1) the position of the implants did not interfere in the transmission of stress in bone tissue, (2) the positioning of the implants in regions 11-21 presented lower stress values in the implants and higher stress in the crown, and (3) the use of cantilever does not increase stress on implants, crown, and bone tissue.

Conflict of Interest

None declared.

\section{References}

1 Vailati F, Belser UC. Replacing four missing maxillary incisors with regular- or narrow-neck implants: analysis of treatment options. Eur J Esthet Dent 2007;2(1):42-57

2 Brandão de Holanda KA, Armini Caldas R, Amaral M, et al. Biomechanical evaluation of anterior implants associated with titanium and zirconia abutments and monotype zirconia implants. J Prosthodont Res 2021;65(1):73-77

3 Gredes T, Kubasiewicz-Ross P, Gedrange T, Dominiak M, Kunert-Keil C. Comparison of surface modified zirconia implants with commercially available zirconium and titanium implants: a histological study in pigs. Implant Dent 2014; 23(4):502-507

4 Cionca N, Hashim D, Mombelli A. Zirconia dental implants: where are we now, and where are we heading? Periodontol 2000 2017;73(1):241-258

5 Porto OCL, Silva BSF, Silva JA, et al. CBCT assessment of bone thickness in maxillary and mandibular teeth: an anatomic study. J Appl Oral Sci 2020;28:e20190148

6 Wakimoto M, Matsumura T, Ueno T, Mizukawa N, Yanagi Y, Iida S. Bone quality and quantity of the anterior maxillary trabecular bone in dental implant sites. Clin Oral Implants Res 2012;23(11):1314-1319
7 Corrêa CB, Margonar R, Noritomi PY, Vaz LG. Mechanical behavior of dental implants in different positions in the rehabilitation of the anterior maxilla. J Prosthet Dent 2014;111(4):301-309

8 Torcato LB, Pellizzer EP, Verri FR, Falcón-Antenucci RM, Batista VE, Lopes LF. Effect of the parafunctional occlusal loading and crown height on stress distribution. Braz Dent J 2014; 25(6):554-560

9 Pham NQ Gonda T, Takahashi T, Maeda Y. The influence of bone loss on peri-implant bending strain under overdentures. Int J Oral Maxillofac Implants 2019;34(4):900-906

10 Borie E, Leal E, Orsi IA, Salamanca C, Dias FJ, Weber B. Influence of transmucosal height in abutments of single and multiple implant-supported prostheses: a non-linear three-dimensional finite element analysis. Comput Methods Biomech Biomed Engin 2018;21(1):91-97

11 Bramanti E, Cervino G, Lauritano F, et al. FEM and von mises analysis on prosthetic crowns structural elements: evaluation of different applied materials. ScientificWorldjournal 2017; 2017:1029574

12 Cervino G, Fiorillo L, Arzukanyan AV, Spagnuolo G, Campagna P, Cicciù M. Application of bioengineering devices for stress evaluation in dentistry: the last 10 years FEM parametric analysis of outcomes and current trends. Minerva Stomatol 2020; 69(1):55-62

13 Cicciù M, Cervino G, Milone D, Risitano G. FEM Analysis of dental implant-abutment interface overdenture components and parametric evaluation of Equator ${ }^{\circledR}$ and Locator ${ }^{\circledR}$ prosthodontics attachments. Materials (Basel) 2019;12(4):592

14 Cicciù M, Risitano G, Maiorana C, Franceschini G. Parametric analysis of the strength in the "Toronto" osseous-prosthesis system. Minerva Stomatol 2009;58(1-2):9-23

15 Freitas da Silva EV, Dos Santos DM, Sonego MV, de Luna Gomes JM, Pellizzer EP, Goiato MC. Does the presence of a cantilever influence the survival and success of partial implant-supported dental prostheses? systematic review and metaanalysis. Int J Oral Maxillofac Implants 2018;33(4):815-823

16 Moris ICM, Faria ACL, de Mattos MdaG, Ribeiro RF, Rodrigues RC. Mechanical analysis of conventional and small diameter conical implant abutments. J Adv Prosthodont 2012;4(3):158-161

17 Pesqueira AA, Goiato MC, Filho HG, et al. Use of stress analysis methods to evaluate the biomechanics of oral rehabilitation with implants. J Oral Implantol 2014;40(2):217-228

18 Bastos JMC, Bordin D, Vasconcellos AA, et al. Influence of cantilever position and implant connection in a zirconia custom implant-supported fixed partial prosthesis: in silico analysis. Rev Odontol UNESP 2018;47:223-229

19 Irandoust S, Müftü S. The interplay between bone healing and remodeling around dental implants. Sci Rep 2020; 10(1):4335

20 Chavarri-Prado D, Brizuela-Velasco A, Álvarez-Arenal Á, et al. The bone buttress theory: the effect of the mechanical loading of bone on the osseointegration of dental implants. Biology (Basel) 2020;10(1):12

21 Cicciù M, Bramanti E, Cecchetti F, Scappaticci L, Guglielmino E, Risitano G. FEM and Von Mises analyses of different dental implant shapes for masticatory loading distribution. Oral Implantol (Rome) 2014;7(1):1-10

22 Verri FR, Santiago JF Jr, Almeida DA, et al. Biomechanical three-dimensional finite element analysis of single implant-supported prostheses in the anterior maxilla, with different surgical techniques and implant types. Int J Oral Maxillofac Implants 2017;32(4):e191-e198

23 Hsu ML, Chen FC, Kao HC, Cheng CK. Influence of off-axis loading of an anterior maxillary implant: a 3-dimensional finite element analysis. Int J Oral Maxillofac Implants 2007; 22(2):301-309 
24 Dos Santos Marsico V, Lehmann RB, de Assis Claro CA, et al. Three-dimensional finite element analysis of occlusal splint and implant connection on stress distribution in implant-supported fixed dental prosthesis and peri-implantal bone. Mater Sci Eng C 2017;80:141-148

25 Teixeira MF, Ramalho SA, de Mattias Sartori IA, Lehmann RB. Finite element analysis of 2 immediate loading systems in edentulous mandible: rigid and semirigid splinting of implants. Implant Dent 2010;19(1):39-49

26 Misch CE, Bidez MW, Sharawy M. A bioengineered implant for a predetermined bone cellular response to loading forces. A literature review and case report. J Periodontol 2001;72(9): 1276-1286

27 Cehreli M, Duyck J, De Cooman M, Puers R, Naert I. Implant design and interface force transfer. A photoelastic and straingauge analysis. Clin Oral Implants Res 2004;15(2):249-257
28 Cicciù M, Cervino G, Milone D, Risitano G. FEM Investigation of the stress distribution over mandibular bone due to screwed overdenture positioned on dental implants. Materials (Basel) 2018;11(9):1512

29 Çaglar A, Bal BT, Karakoca S, Aydın C, Yılmaz H, Sarısoy S. Three-dimensional finite element analysis of titanium and yttrium-stabilized zirconium dioxide abutments and implants. Int J Oral Maxillofac Implants 2011;26(5):961-969

30 Lauritano F, Runci M, Cervino G, Fiorillo L, Bramanti E, Cicciù M. Three-dimensional evaluation of different prosthesis retention systems using finite element analysis and the Von Mises stress test. Minerva Stomatol 2016;65(6):353-367

31 Ereifej N, Rodrigues FP, Silikas N, Watts DC. Experimental and FE shear-bonding strength at core/veneer interfaces in bilayered ceramics. Dent Mater 2011;27(6):590-597 